\title{
On the measurement of product quality in intra-industry trade
}

\begin{abstract}
The world has witnessed a dramatic increase in trade over the last forty years. Much of this growth in trade is intra-industry in nature. A relatively recent development in the intraindustry trade (IIT) literature is the measurement of the simultaneous import and export of quality-differentiated products, commonly known as vertical and horizontal IIT. In this paper we compare the Greenaway, Hine and Milner (1994) and Fontagné and Freudenberg (1997) approaches to disentangling vertical and horizontal intra-industry trade and examine some of the implications of employing simple ratios to define the boundary between product quality types. We present a complementary approach based on the traditional Grubel and Lloyd (GL) index and demonstrate with numerical examples its versatility and applicability at the product level. (C) 2006 The Kiel Institute.
\end{abstract}

Keyword: Globalization, Product quality, Vertical and horizontal intra-industry trade 